\title{
Hypogonadotropic hypogonadism and pituitary hypoplasia as recurrent features in Ulnar-Mammary syndrome
}

\author{
Elena Galazzi 1,2, *, Paolo Duminuco 1,*, Mirella Moro1, Fabiana Guizzardi', Nicoletta Marazzi, \\ Alessandro Sartorio ${ }^{3,4}$, Sabrina Avignone5, Marco Bonomi ${ }^{1,2}$, Luca Persani ${ }^{1,2}$ and Maria Teresa Bonati ${ }^{6}$ \\ ${ }^{1}$ IRCSS Istituto Auxologico Italiano, Laboratory of Endocrine and Metabolic Research and Division of Endocrine and Metabolic Diseases, Milan, Italy \\ ${ }^{2}$ Department of Clinical Sciences and Community Health, Università degli Studi, Milan, Italy \\ ${ }^{3}$ IRCSS Istituto Auxologico Italiano, Laboratory for Auxo-Endocrinological Research, Milan, Italy \\ ${ }^{4}$ Division of Auxology and Metabolic Diseases, IRCSS Istituto Auxologico Italiano, Piancavallo (VB), Italy \\ ${ }^{5}$ Fondazione IRCCS Ca' Granda Ospedale Maggiore Policlinico di Milano, U.O.C Neuroradiologia, Milan, Italy \\ ${ }^{6}$ IRCCS Istituto Auxologico Italiano, Service of Medical Genetics, Milan, Italy
}

Correspondence should be addressed to M T Bonati or L Persani: mt.bonati@auxologico.it or luca.persani@unimi.it

*(E Galazzi and P Duminuco contributed equally to this work)

\begin{abstract}
Ulnar-mammary syndrome (UMS) is characterized by ulnar defects, and nipple or apocrine gland hypoplasia, caused by TBX3 haploinsufficiency. Signs of hypogonadism were repeatedly reported, but the mechanisms remain elusive. We aim to assess the origin of hypogonadism in two families with UMS. UMS was suspected in two unrelated probands referred to an academic center with delayed puberty because of the evident ulnar ray and breast defects in their parents. Clinical, biochemical and genetic investigations proved the existence of congenital normosmic $\mathrm{IHH}(\mathrm{nIHH})$ associated with pituitary hypoplasia in the two probands who were heterozygous for novel TBX3 pathogenic variants. The mutations co-segregated with delayed puberty, midline defects (nose, teeth and tongue anomalies) and other variable features of UMS in the two families (absent axillary hairs and nipple hypoplasia, asymmetrical features including unilateral ulnar or renal abnormalities). The combined analysis of these findings and of the previous UMS reports showed delayed puberty and other signs of hypogonadism in 79 and $37 \%$ of UMS males, respectively. Proband 1 was followed up to adulthood with persistence of $\mathrm{nIHH}$. In conclusion, UMS should be suspected in patients with delayed puberty and midline defects, including pituitary hypoplasia, in the presence of mild cues for TBX3 mutation, even in the absence of limb malformations. In addition, TBX3 should be included among candidate genes for congenital $\mathrm{nIHH}$.
\end{abstract} Key Words

Key Words
- puberty
- pituitary
- hypothalamus
- pediatric endocrinology
- rare diseases/syndromes
- neuroendocrinology
- midline defects
- micropenis
- nipple hypoplasia
- TBX3

\section{Introduction}

The TBX3 gene encodes a member of the T-box family of transcription factors acting as a repressor of target gene expression. Tbx3 has a role in the specification of posterior limb mesoderm and in the development of the dorsoventral limb axis. The same inductive interaction between epithelial tissue and underlying mesenchyme demonstrated for limb buds had been found in breast, tooth and genital development (1). Recently, it has also been reported that Tbx3 functionality is required for the hormone sensing cell lineage in the mammary epithelium (2).

In humans, loss of Tbx3 function causes ulnar ray defects and hypoplasia/aplasia of the breasts/nipples,

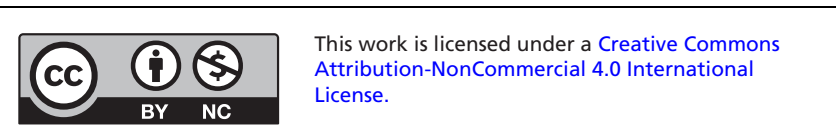


an association that characterizes the ulnar-mammary syndrome (UMS, MIM \#181450). Expressivity of these features is usually asymmetrical and variable: as for the upper limbs, from shortening or clinodactyly of the fifth finger to the absence of the third to fifth fingers and ulna with radial shortening or complete absence of the radius/ ulna and hand in the most severe cases. All patients exhibit diminished or absent axillary hair and reduced or absent perspiration as further signs of the involvement of apocrine glands; lactation may be absent (3).

Despite the lack of association between TBX3 variants with isolated hypogonadotropic hypogonadism (IHH), signs of hypogonadism, including bilateral cryptorchidism, micropenis and delayed puberty, have been repeatedly reported among patients with UMS (3, $4,5,6,7,8,9)$. Moreover, the constellation of endocrine manifestations in UMS patients includes short stature, growth hormone deficiency and obesity (3, 5, 6, 10, 11, 12); however, information on hormonal parameters is scarce to date in UMS patients.

In this study, we report on two probands who presented with delayed puberty and were then found to have novel TBX3 pathogenic variants segregating in their families with variable UMS phenotype. Hormonal studies were consistent with congenital normosmic IHH (nIHH), while brain/pituitary malformations were recurrently found in affected patients. Since no variants in candidate genes for $\mathrm{HH}$ or hypopituitarism were found, these features can be considered part of the TBX3 loss-of-function-related clinical spectrum. Therefore, endocrinologists should consider the possibility of a TBX3 pathogenic variant in patients presenting with delayed puberty or short stature associated with subtle UMS features and peculiar midline defects.

\section{Subjects and methods}

\section{Patients}

Both probands were referred for delayed puberty and midline defects. The patients underwent clinical evaluation, baseline and dynamic hormonal testing, as well as genetic analyses after informed consent of the parents. Gonadotrophin-releasing hormone $(\mathrm{GnRH})$ test $(100 \mu g$, Relefact, gonadorelin; Sanofi) was performed using standard procedures (intravenous injection and blood sample collection for luteinizing hormone (LH) and follicle-stimulating hormone ( $\mathrm{FSH})$ determinations at baseline and $\left.+15^{\prime},+30^{\prime},+60^{\prime},+90^{\prime},+120^{\prime}\right)$. Serum LH and FSH concentrations were measured by specific immunoassays (Elecsys, Roche).
As in UMS each pathogenic variant is known to be unique to the family, all family members were enrolled in the study in order to perform a co-segregation analysis of the predicted pathogenic variants.

\section{Sequencing}

The genomic DNA was extracted from peripheral blood lymphocytes using GeneCatcher gDNA Automated Blood Kit, $96 \times 10 \mathrm{~mL}$ (Invitrogen, Life Technologies). Analysis was performed by targeted next-generation sequencing (NGS) on an Illumina MiSeq sequencer (Illumina) following previously reported methods (13) and using a gene panel which includes known causal genes for IHH and hypopituitarism: CHD7, NROB1, DUSP6, FSHB, FEZF1, NSMF, LHB, FGF17, PROK2, FGF8, PROKR2, FGFR1, SEMA3A, FLRT3, SEMA3E, GNRH1/2, SEMA7A, SOX10, GNRHR, SOX2, HS6ST1, HESX1, SPRY4, IL17RD, TAC3, ANOS1 (KAL1), TACR3, KISS1, WDR11, KISS1R, LHX3; LHX4, PUO1F1, PROP1, GH1/2, GHRH, GHRHR, IGSF1. The total coverage of the target genes was $>80 \%$. All uncovered regions were recovered by Nextera DNA Library Preparation Kit (Illumina).

TBX3 was sequenced by either Sanger sequencing or NGS, while the $5^{\prime}$ and 3' UTRs of the gene were sequenced by Sanger.

\section{Variant analysis}

Neither of the TBX3-identified genetic variants had been reported in the SNP database or in the Exome Aggregation Consortium database. The missense variant was predicted to be damaging by eight in silico prediction tools - SIFT (scale-invariant feature transform), PolyPhen2 HVAR, PolyPhen2 HDIV, LRT (likelihood ratio test), MutationTaster, Mutation Assessor, FATHMM (functional analysis through hidden Markov models), PROVEAN and CADD (complete annotation dependent depletion) (14).

\section{UMS database}

We analyzed the previous clinical reports of UMS patients who were carriers of a TBX 3 pathogenic variant, with special focus on endocrine features and midline or asymmetrical defects. Facial resemblance across unrelated UMS patients (broad/beaked/bifid nasal tip and jaw hypoplasia) (12), bilobated tongue tip and teeth anomalies, were classified as midline defects. The clinical data from all UMS families are reported in the supplemental materials.

This work is licensed under a Creative Commons Attribution-NonCommercial 4.0 International License. 
A

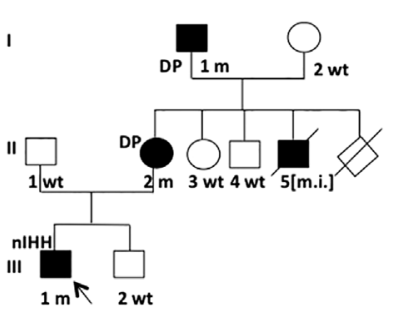

B

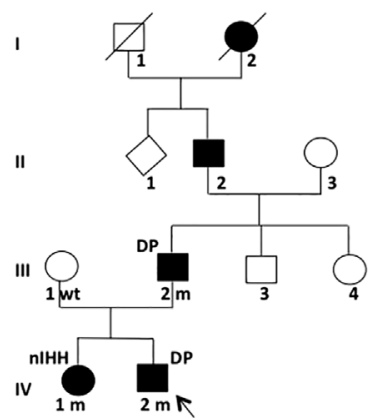

C

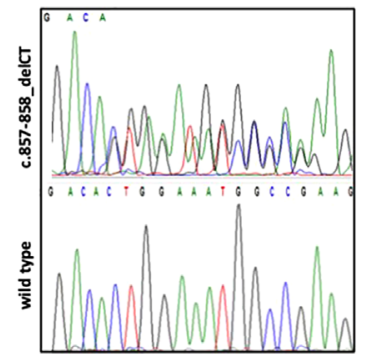

D

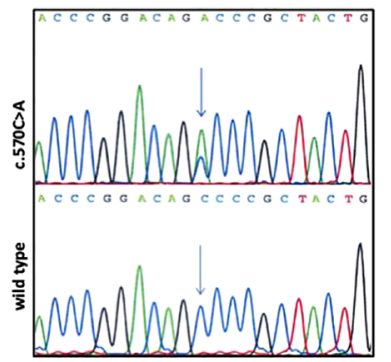

E

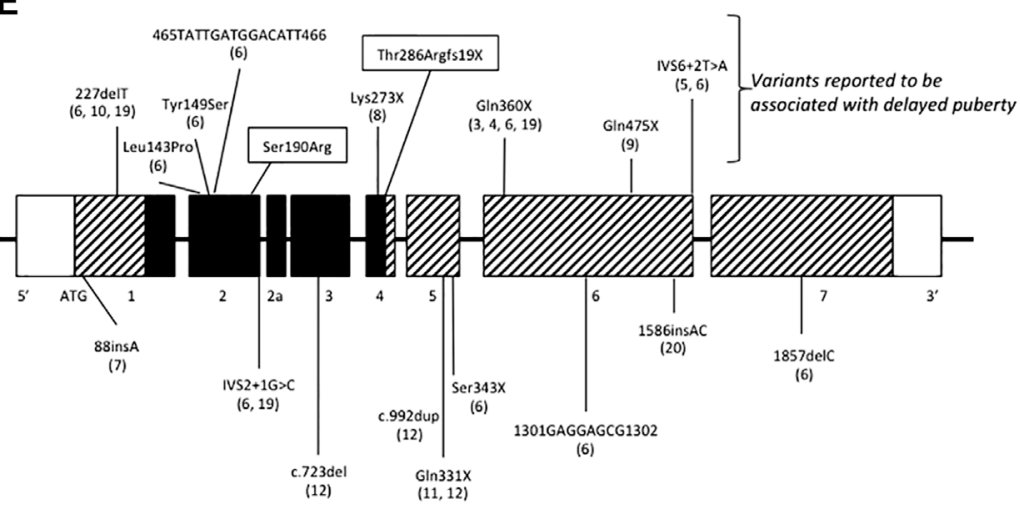

Figure 1

Genetic findings. Pedigree of the families are shown in panels A and B. Subjects affected by variable UMS features are reported with filled symbols and the presence of $\mathrm{nIHH}$ and/or delayed puberty (DP) is indicated. TBX3 genotype is reported close to each symbol with the following code: $\mathrm{m}$, mutated; wt, wild-type; m.i., mutation inferred (C and D) Electropherograms of the TBX3 gene sequence of the probands (upper panel) and WT subjects (lower panel). (E) Genomic structure of TBX3 includes seven exons. The gene contains untranslated sequences (white boxes) and protein-encoding sequences (striped boxes), the highly conserved T-box sequences are indicated by the black boxes; exon 2a is alternatively transcribed (modified from (3)). The approximate position of the pathogenic variants is indicated and variants associated with delayed puberty are distributed above the gene structure. Rectangles identify the novel pathogenic variants here described.

\section{Results}

\section{Clinical reports}

\section{Family A}

A 14-year-old boy (III-1, Figs $1 \mathrm{~A}$ and 2A, B, C, D and E) was referred for endocrine evaluation because of delayed puberty, micropenis ( $3 \mathrm{~cm}$ stretched length), dyslipidemia and obesity (BMI $31.2 \mathrm{~kg} / \mathrm{m}^{2}$, >95th percentile).

He previously underwent cerebral and spinal magnetic resonance imaging (MRI) for urinary incontinence that besides syringomyelia (Fig. 1C) showed pituitary gland hypoplasia (Fig. 3A), a thin pituitary stalk (Fig. 3A and B) and skull base dysmorphism with clivus horizontalization, consistent with an Arnold Chiari (AC) type 1 malformation (Fig. 3C). He also exhibited peculiar asymmetrical features (Fig. 3C and D). He had normal pituitary functions (insulinlike growth factor 1 (IGF1)=201 ng/mL, n.v. 141-669; thyroid-stimulating hormone $(\mathrm{TSH})=1.85 \mathrm{mU} / \mathrm{L}$, n.v. $0.27-4.5$; free $\mathrm{T} 4=15.9 \mathrm{pmol} / \mathrm{L}$, n.v. $11.5-24.5$; prolactin
$(\mathrm{PRLb})=6.1 \mathrm{ng} / \mathrm{mL} ; \quad$ n.v. 2.5-17) with prepubertal response of $\mathrm{LH}$ and FSH to GnRH test, low inhibin B and undetectable total testosterone (TTe) levels (Table 1). He was normosmic at Brief-Smell Identification test (B-SIT) and normal central olfactory structures were confirmed using MRI. His karyotype was $46, \mathrm{XY}$. At the age of 15 years, he underwent decompression surgery for AC1 malformation, with diuresis improvement.

He received testosterone enanthate treatment for 9 months, but at 16 years and 11 months, the testis volume was -4.9 SDS (according to Joustra et al. (15)), and puberty was induced with FSH priming (75 IU for three times a week for 4 months) (16), followed by an induction scheme with FSH (150IU for 3 times a week). Human chorionic gonadotrophin was given starting from a dose of 1000 up to 2000 UI twice a week with increments of 500 UI every 6 months and up-titrating the dose according to TTe levels $(4,17,18)$. During the puberty induction, a progressive rise of testosterone and inhibin $B$ was seen (Table 1). https://ec.bioscientifica.com

https://doi.org/10.1530/EC-18-0486 (c) 2018 The authors Published by Bioscientifica Ltd
This work is licensed under a Creative Commons Attribution-NonCommercial 4.0 International License. 

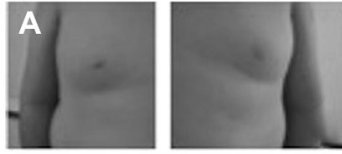

B
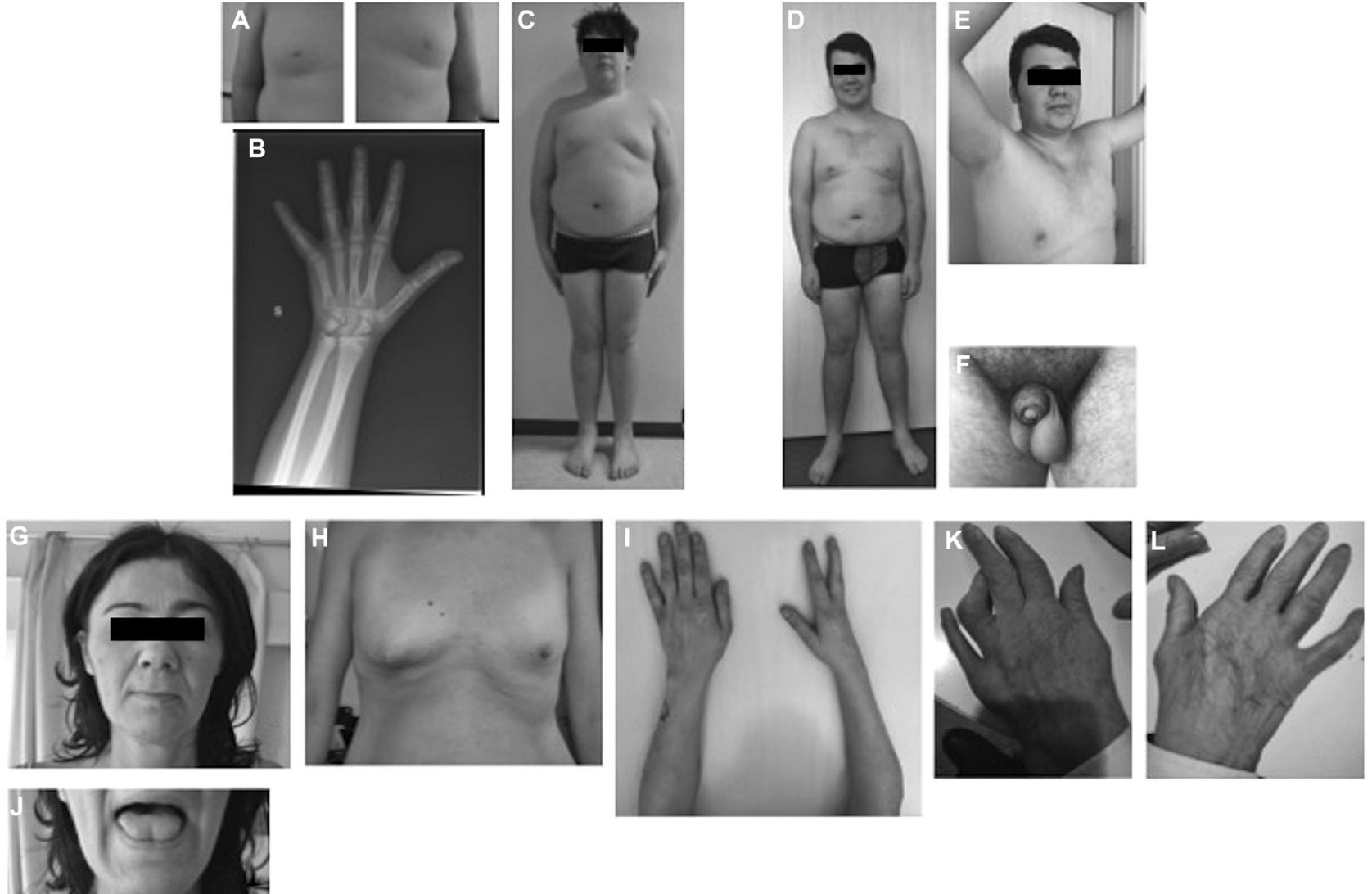

Figure 2

Clinical features of family A (signed consent for picture publication was obtained from all members). (A) Details of the proband's nipples at the age of 14. (B) Wrist X-ray showing normal skeletal morphology of hand and forearm. Pictures of the proband at the age of 14 (C) and at 18 years (D), showing prominent central obesity, inverted right nipple and hypoplasia of the left one. At the age of 18 years, axillary hairs were absent with no sweating from the armpits (E), despite adult testes volume and pubic hair (F). Face of the proband's mother (II-2, family A), showing asymmetric palpebral fissures and broad nasal tip (G). She had bilateral mammary gland hypoplasia, more evident on the left side (H) that precluded lactation onset after her two pregnancies. She had absence of IV and V digits of the left hand, ipsilateral ulnar hypoplasia (I) and bilobated tongue (J). Hands of the grandfather I-1 $(\mathrm{K}, \mathrm{L})$ (see details in the Clinical Report).

After 15 months, he gained an adult testicular volume (testes $20-25 \mathrm{~mL}$ ) and penis length $(9 \mathrm{~cm}$ stretched length and $3.5 \mathrm{~cm}$ diameter). At 18 years, he presented with a Tanner stage P5G5A1, and the gonadotropin treatment was withdrawn (Fig. 2E and F). Hypo-testosteronemia recurred (Table 1), and he complained of poor school performance and fatigue that improved during subsequent transdermal testosterone replacement therapy. Absent axillary sweating was repeatedly reported.

His maternal grandfather (I-1, Fig. 1A) was reported to have had pubertal spurt at 17 years and finger hypoplasia. We were able to evaluate his clinical records and photographs of his hands, documenting right fifth finger clinodactyly, left fourth finger camptodactyly and hypoplasia of the left fifth finger distal phalanx (Fig. 2M). His mother (II-2), who reported late menarche (at 14 years), had an asymmetric right ulnar deformity

https://ec.bioscientifica.com
https://doi.org/10.1530/EC-18-0486 2018 The authors

and left breast hypoplasia, with other phenotypic features consistent with UMS (Fig. 2G, H, I, J, K and L), such as almost absent axillary hairs with no sweating from the armpits.

\section{Family B}

Proband (IV-2, Fig. 1B) was assessed at the age of 14 years and 1 month because of short stature (height=-1.59 SDS; delta SDS target height $(\mathrm{TH})=-2.07)$. His bone age $(\mathrm{BA}=12.8 / 12$ on radius, ulnar and short bones (RUS) and carpal(CARP), Tanner-Whitehouseevaluation) was delayed by 1 year and 5 months compared to his chronological age $(\mathrm{CA}=14.1 / 12)$. Hormonal testing revealed euthyroid hyperthyrotropinemia $(\mathrm{TSH}=14.1 \mathrm{mU} / \mathrm{L}$, n.v. 0.27-4.0, FT4=17.9 pmol/L, n.v. 11.5-24.5) with negative antithyroid antibodies and without signs of thyroiditis on

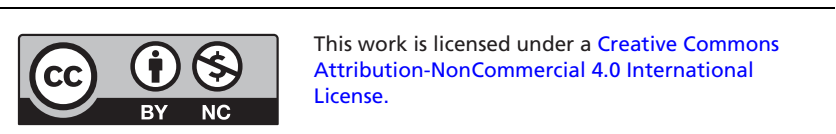



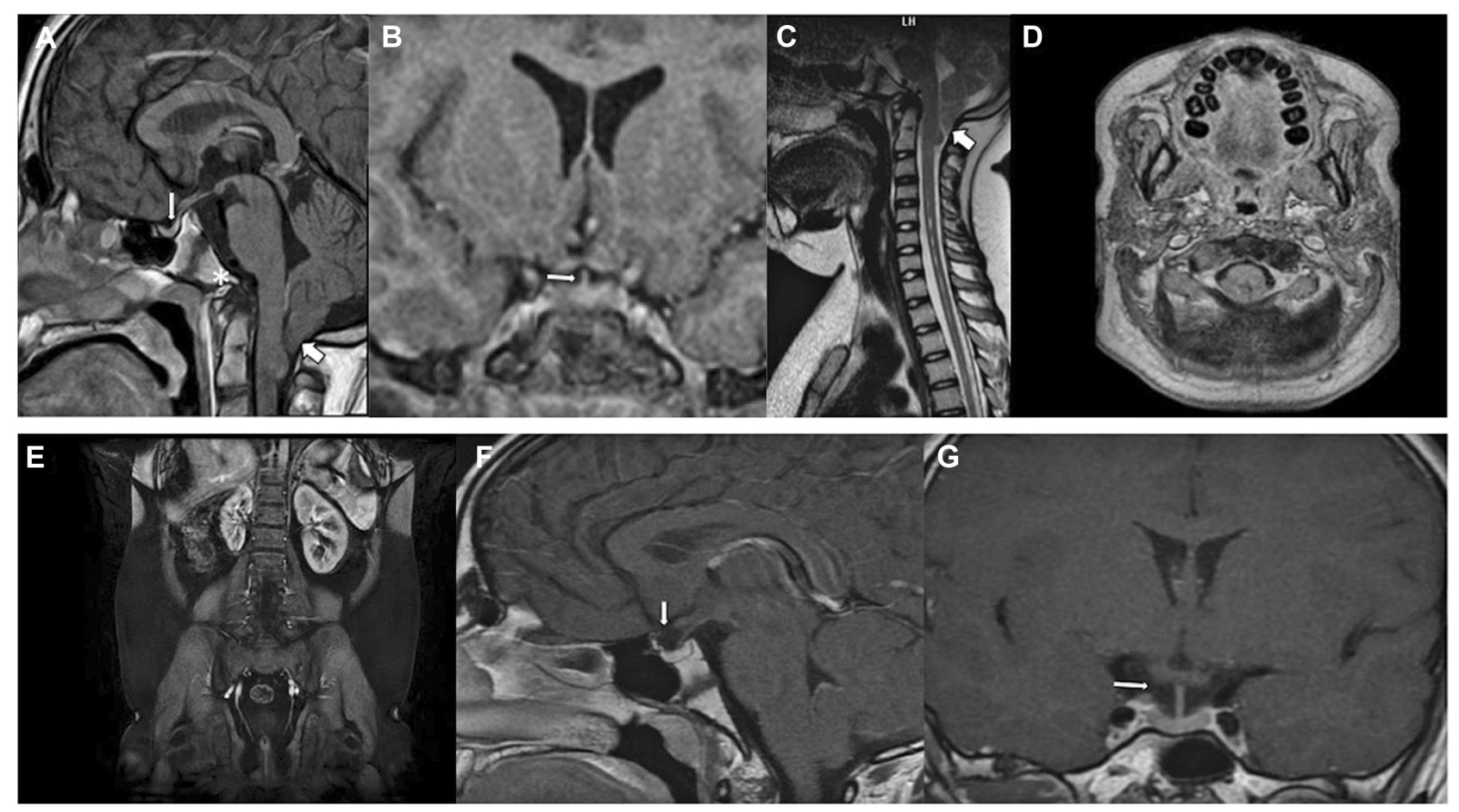

Figure 3

MRI imaging. Patient III-1 (family A): (A) sagittal T1 W post-contrast image showing hypoplasic pituitary gland (white small arrow); pituitary stalk was thin and flattened on the posterior wall of sella turcica. (B) Coronal T1 W post-contrast image showing thin and median stalk (small white arrow). (A) and (C): sagittal T1 W post-contrast image and sagittal T2 W image of cervical spine showing ectopic cerebellar tonsils (white arrow), syringomyelia, skull base dysmorphism with clivus horizontalization (white asterisk) consistent with Arnold Chiari type I malformation. (D) Abdominal MRI with evident kidney asymmetry (right hypoplasia). (E) Skull MRI showing crowded right upper dental arch. Patient IV-2 (family B): (F) sagittal T1 W post-contrast image and (G) coronal T1 W post-contrast image showing hypoplastic adenohypophysis according to the age of the proband $(4 \times 4.7 \mathrm{~mm}) ; \mathrm{normal}$ pituitary stalk.

ultrasound. The other pituitary hormones were normal (prolactin (PRL) $8.4 \mathrm{ng} / \mathrm{mL}$, n.v.: 2.5-17; IGF1 $182 \mathrm{ng} / \mathrm{mL}$; n.v.: 152-324), but serum determinations showed $\mathrm{IHH}$ $(\mathrm{TTe}=0.31 \mathrm{nmol} / \mathrm{L} ; \quad \mathrm{FSH}=1.3 \mathrm{U} / \mathrm{L}, \quad \mathrm{LH}<0.3 \mathrm{U} / \mathrm{L})$. The pituitary MRI showed anterohypophysis hypoplasia with normal pituitary stalk (Fig. 3D and E).

The proband had normal neonatal growth parameters, and his karyotype performed on amniotic liquid for advanced maternal age was 46,XY. He underwent surgery at the age of 5 years for short frenulum of the tongue. At 14 years, he was evaluated for a suspected arrhythmia.

Physical examination showed high forehead, epicanthic folds, broad nasal tip, anteverted nostrils, bilobated tongue tip, high palate, slight microretrognathia, asymmetric ears, hypoplasia of nipples, more evident on the left side, and absence of axillary hairs. He was normosmic at B-SIT and referred absent sweating. A clinical re-examination at 15 years and 3 months confirmed short stature (height $=-1.85$ SDS; delta SDS $\mathrm{TH}=-2.33$ ) with

Table 1 Evaluation of gonadal axis of patient III-erom family A, before and after puberty induction.

\begin{tabular}{|c|c|c|}
\hline & \multicolumn{2}{|c|}{ At diagnosis } \\
\hline Age (years) & \multicolumn{2}{|c|}{14.0} \\
\hline GnRH test & Basal & Peak \\
\hline LH (IU/L) & 0.1 & 0.4 \\
\hline FSH (IU/L) & 0.7 & 2.9 \\
\hline Testosterone (nmol/L) & \multicolumn{2}{|c|}{0.05} \\
\hline Inhibin B (pg/mL) adult n.v.: $80-400$ & \multicolumn{2}{|c|}{70} \\
\hline Testes $(\mathrm{mL})$ & \multicolumn{2}{|c|}{$3-3$} \\
\hline
\end{tabular}

n.v., normal value. (c) 2018 The authors Published by Bioscientifica Ltd

\begin{tabular}{|c|c|c|c|c|}
\hline \multicolumn{2}{|c|}{$\begin{array}{l}\text { After testosterone } \\
\text { enanthate priming }\end{array}$} & \multicolumn{2}{|c|}{$\begin{array}{c}\text { After induction of } \\
\text { puberty with FSH + hCG }\end{array}$} & \multirow{2}{*}{$\begin{array}{c}\text { Two years later } \\
18.11\end{array}$} \\
\hline \multicolumn{2}{|c|}{15.5} & \multicolumn{2}{|c|}{16.11} & \\
\hline Basal & Peak & Basal & Peak & \\
\hline 0.5 & 4.7 & 2.1 & 12.1 & \\
\hline 1.5 & 3.2 & 1.2 & 1.9 & \\
\hline \multicolumn{2}{|c|}{0.65} & \multicolumn{2}{|c|}{20.66} & 7.5 \\
\hline \multicolumn{2}{|c|}{115} & \multicolumn{2}{|c|}{170} & 166 \\
\hline \multicolumn{2}{|c|}{$3-4$} & \multicolumn{2}{|c|}{$20-25$} & $20-25$ \\
\hline
\end{tabular}

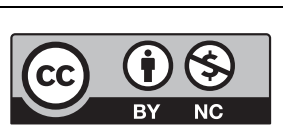

This work is licensed under a Creative Commons Attribution-NonCommercial 4.0 International License. 
a growth velocity still in the prepubertal range (growth rate $=4.5 \mathrm{~cm} /$ year, SDS growth rate $=-1.87$ ). At physical examination, he was prepubertal (testes $3 \mathrm{~mL}$ bilaterally, -2.8 SDS), $\mathrm{nIHH}$ was again confirmed $(\mathrm{FSH}=1.3 \mathrm{U} / \mathrm{L}$, $\mathrm{LH}=0.3 \mathrm{U} / \mathrm{L}, \mathrm{TTe}=0.41 \mathrm{nmol} / \mathrm{L}$ ) and puberty was then induced at 16.8 years, following the same protocol of proband of family A. Echocardiogram and ultrasound of the abdomen carried out after the genetic evaluation showed normal findings.

On clinical examination, the proband's elder sister, 20 years old, and the father, 59 years old (IV-1 and III-2, respectively, Fig. 1B), exhibited similar facial features with broad nasal tip and bilobated tongue tip, as well as absent axillary hairs and sweating, and bilateral symmetrical nipple hypoplasia. The father exhibited ulnar hypoplasia and absence of the left fourth and fifth fingers. His puberty was delayed and had been induced by testosterone priming for 4 months at 16 years of age. He was normosmic at B-SIT. The circulating TSH was $3.48 \mathrm{mU} / \mathrm{L}$ with negative anti-thyroid antibodies. The proband's sister had normal menses but exhibited absence of the right breast and moderate hypoplasia of the left one at ultrasound. She had been diagnosed with idiopathic GH deficiency ( $\mathrm{GH}$ peak was blunted either after clonidine or insulin tolerance tests: 4.3 or $2.0 \mathrm{ng} / \mathrm{mL}$, respectively) and received $\mathrm{rhGH}(0.2 \mathrm{mg} / \mathrm{Kg} / 7$ days a week) for 6 years from the age of 9.9 years. Her karyotype was 46,XX. Brain MRI displayed a slight downward displacement of the cerebellar tonsils but normal pituitary gland and stalk. She had normal thyroid function with absent anti-thyroid antibodies. She reported delayed menarche (at 13.9 years). Kidney, ovary and uterus abnormalities were ruled out by transabdominal US. The circulating TSH was $4.42 \mathrm{mU} / \mathrm{L}$ with normal FT4 (13.7 pmol/L) and negative anti-thyroid antibodies.

The paternal grandfather and the great grandmother (II-2 and I-2, Fig. 1B) were reported to lack axillary hairs. The grandfather was also reported to have nipple hypoplasia, whereas the great grandmother was able to lactate.

\section{Genetic findings}

\section{Family A}

A heterozygous frameshift variant, c.857-858 del CT, in exon 4 of TBX3 gene (NM_005996, hg19), was found in the proband and his mother (Fig. 1C), resulting in the substitution of the second-last amino acid of the T-box domain and a premature stop codon after 19 amino acids (p.T286RfsX19) (Fig. 1E). Benign variants were identified in TBX3 $5^{\prime}$ and $3^{\prime}$ UTR and deposited in the Figshare database Repository 2018 (Supplementary Table 1, see section on supplementary data given at the end of this article)

Pathogenic variants in $\mathrm{IHH}$ and pituitary candidate genes were ruled out by target NGS. The TBX3 variant was identified in the grandfather I-1, whereas the remaining family members I-2, II-1, II-3, II-4 and III-2 showed a WT genotype (Fig. 1A). Mutation was inferred for subject II-5, who, having been born premature and having died shortly thereafter, was reported to show a hand malformation.

\section{Family B}

NGS of TBX3, IHH and pituitary gene panel, and TSHR was performed on the proband, who was found to carry a heterozygous missense variant c.570C>A, p.S190R in exon 2 of TBX3 gene (NM_005996, hg19 g.115118771) (Fig. 1E), which is predicted to be pathogenic by eight different databases, as deposited in the Figshare database Repository 2018 (Supplementary Table 2). The proband's sister was found to carry the TBX3 missense variant, which was inherited from the father. Benign variants were identified in TBX3 5' and 3' UTR (Supplementary Table 1).

Interestingly, the proband and his sister were heterozygous for the variant c.959G >A, p.S320N in TSHR gene (NM_000369, rs772172530, hg19 g.81609361), which was inherited from their father, probably explaining their mild non-autoimmune hypothyroidism.

\section{TBX3 genotype/phenotype correlations}

Clinical findings of UMS patients with TBX3 mutations belonging to the 17 previously reported families and the two families here described are shown in Supplementary Table 3. The frequency of endocrine features as well as congenital malformations (classified into midline defects, asymmetric malformations, breast and limb defects) is shown in Fig. 4. Noteworthy, differently from the midline (Fig. 4B) and other congenital malformations (Fig. 4B, C and $\mathrm{D}$ ), endocrine defects appear more penetrant in males than in females (Fig. 4A). Furthermore, UMS phenotype is frequently characterized by multiple midline defects involving the face and several other areas (Fig. 4B).

Most of the TBX3 pathogenic variants (n. 16) are predicted to cause a premature truncated protein, being frameshift (n. 11) or nonsense (n. 5) mutations. Three missense mutations only have been reported so far, including ours (Fig. 1E). To perform genotype/phenotype correlations, each of the 19 TBX3 pathogenic variant has https://ec.bioscientifica.com

https://doi.org/10.1530/EC-18-0486 (c) 2018 The authors Published by Bioscientifica Ltd
This work is licensed under a Creative Commons Attribution-NonCommercial 4.0 International License. 


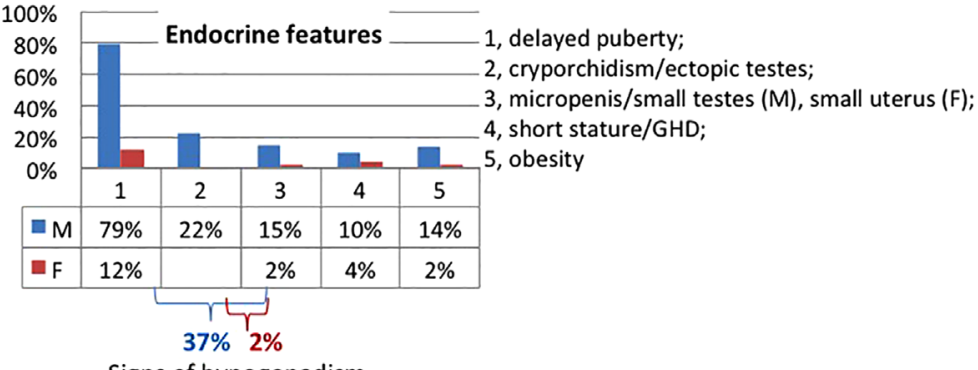

Signs of hypogonadism

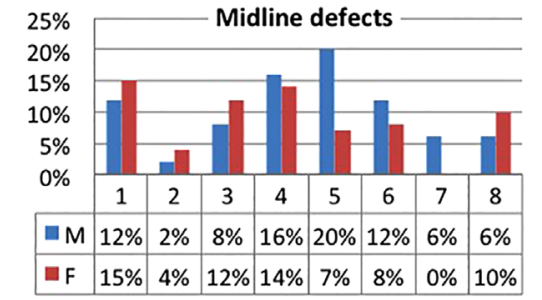

1 , broad/beaked/bifid nasal tip

2 , cleft papate, bifid uvula

3 , bilobated tongue tip/ankyloglossia

4 , teeth anomalies

5, laryngeal, pyloric and anal stenosis or atresia/rectoperineal fistula

6 , pectus carenatum/absence of xiphisternum, scoliosis

7 , cardiac malformations

8 , bifid or shauwl scrotum (M), bicornuate/septate uterus, imperforate hymen (F)

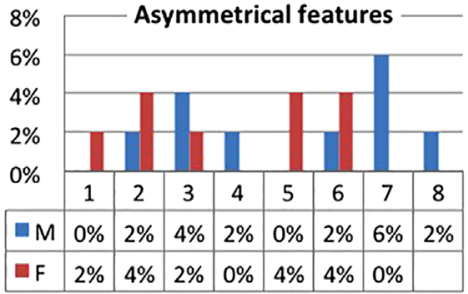

1, unilateral craniofacial hypoplasia; 2 , unilateral absence of eye/ blepharoptosis;

3 , ears' shape asymmetry

4 , unilateral absence of pectoralis muscle;

5 , chest asymmetry;

6 , unilateral kidney hypoplasia or ectopia

7 , unilateral inguinal hernia;

8 , unilateral hydrocele

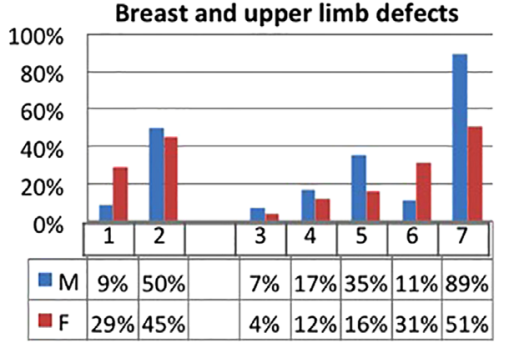

been mapped within the gene. Truncating mutations are distributed all over the gene, whereas the missense ones cluster in exon 2, within the T-box domain (Fig. 1E). There is no clear segregation of particular phenotypes with mutations destroying or truncating the protein before the T-box domain in comparison with those occurring after the DNA-binding domain $(6,21,22)$ (Fig. 1E and Supplementary Table 3). In particular, the majority (59\%) of $T B X 3$ pathogenic variants are associated with delayed puberty. In addition, the phenotypic manifestations appear highly variable even among individuals from the same family.

\section{Clinical features of UMS vs IHH cohorts}

By analyzing the UMS data collected from literature in comparison with those from the IHH cohorts $(17,23,24)$, we found that the male-to-female ratio (M:F) of patients with delayed puberty is higher in UMS than in IHH (M:F=7:1 vs 3-5:1, respectively) (Fig. 4A).

We then found that the prevalence of congenital IHH manifestations in UMS boys, such as bilateral cryptorchidism and micropenis, reaches 22 and 15\%, respectively (Fig. 4A). These percentages are even higher than those found in the Italian cohort of normosmic prepubertal-onset IHH (17.7 and 2.4\%, respectively) (23), and in Pitteloud cohort of $\mathrm{nIHH}$, that were 7 and $8 \%$, respectively (24).

In addition, the prevalence of orofacial cleft and/or tooth agenesis in the syndrome is $31 \%$ and that of renal abnormalities is $6 \%$ (Fig. 4B). These percentages are higher than those found in the Italian cohort of prepubertal onset IHH (9.8 and $0.4 \%$, respectively) (23).
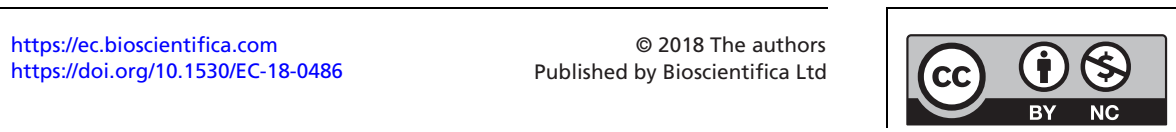


\section{Discussion}

Our findings indicate that delayed puberty due to normosmic hypogonadotropic hypogonadism with pituitary hypoplasia is a recurrent feature in two unrelated families with variable UMS phenotype carrying novel heterozygous variants of TBX3 gene. Physical and developmental abnormalities including signs of hypogonadism and delayed puberty had been previously described in UMS patients (Fig. 4A), but they were poorly characterized $(3,4,5,6,8,9,10,11,12)$. Therefore, $T B X 3$ loss of function is frequently associated with hypogonadism of central origin.

Consistently, three authors $(5,8,9)$ previously described gonadal defects associated with the syndrome (Fig. 1E and Supplementary Table 3). Puberty of patient 1, as described by Schinzel in 1987 (5), was induced by testosterone and gonadotropins without reaching an adult Tanner stage, but hormonal values and brain MRI were not reported. In two prepubertal UMS Japanese brothers, mild gonadotropin deficiency has been described as the cause of the defective development of external genitalia (8), but the absence of clinical and biochemical follow-up does not allow a differentiation between true IHH and congenital delay of growth and puberty (CDGP). Finally, one out of two twins (born from an in vitro fertilization pregnancy) recently described by Tanteles (9) had a prepubertal response to $\mathrm{GnRH}$ test at 15 years, but developed a normal puberty after testosterone priming, thus suggesting a CDGP rather than IHH.

We report on two new TBX3 variants whose deleterious impact is supported by their co-segregation with variable UMS and nIHH features in two families. In patient III-1 (family A), congenital nIHH diagnosis is based on the combination of a prepubertal response to GnRH test after the age of 14 years, the absent clinical response to testosterone priming, the ability to achieve Tanner stage $\mathrm{V}$ after gonadotropins treatment and the decrease of testosterone levels associated with signs and symptoms of hypogonadism after treatment withdrawal (17). Therefore, this patient is the first UMS adult reported to have the classic biochemical and clinical features of congenital nIHH. Similarly, the repetitively low gonadotropin and testosterone levels at 16.8 years of age in the patient IV-2 (family B) are also consistent with the diagnosis of congenital nIHH $(25,26)$. Indeed, we found a large overlap between some features of UMS and congenital IHH. In particular, we show the presence in UMS of a high percentage of midline defects, including those involving brain and pituitary. It is noteworthy that in all four UMS patients, including the present three cases (family A: III-1 and Family B: IV-1 and IV-2), who underwent brain neuroimaging, some sort of brain and/or pituitary malformation has been detected. Both of our probands had a small pituitary, associated in case III-1 with a thin stalk flattened on the posterior wall of sella turcica. Likewise, the only author who previously performed brain MRI in an UMS patient (11) revealed an anterior pituitary hypoplasia with a thin stalk and an ectopic posterior pituitary gland. We found an AC1 malformation in one patient (III-1) and a slight downward displacement of the cerebellar tonsils in a second unrelated one (IV-1). The association of UMS with these variable midline defects at brain MRI is consistent with the known role of T-box family genes in hypothalamic and pituitary development both in humans and in mice $(27,28)$, and with the expression of $T B X 3$ gene in pituitary human tissue (6). One previous study in mice by Trowe et al. (29) showed that $T B X 3$ knockout causes a failure in the infundibulum development, resulting in Rathke's pouch degeneration and pituitary hypoplasia. These effects appear to be the consequence of a de-repression of the sonic hedgehog pathway in the ventral diencephalon combined with an impaired FGF signal from the infundibulum.

In conclusion, midline defects together with absent axillary hairs and nipple hypoplasia are key features of UMS that should be checked in patients with delayed puberty. Neuroimaging seems particularly useful to uncover pituitary and brain malformations that appear specifically associated with the TBX3 loss-of-function phenotype. In addition, $T B X 3$ should be included among the candidate genes for congenital normosmic IHH and its involvement can be suggested in one patient with delayed puberty by the presence of ulnar deformities in other family members.

\section{Supplementary data}

This is linked to the online version of the paper at https://doi.org/10.1530/ EC-18-0486.

\section{Declaration of interest}

The authors declare that there is no conflict of interest that could be perceived as prejudicing the impartiality of the research reported.

\section{Funding}

This study was supported by funds from IRCCS Istituto Auxologico Italiano (Ricerca Corrente grant number 05C202_2012).
() 2018 The authors Published by Bioscientifica Ltd
This work is licensed under a Creative Commons Attribution-NonCommercial 4.0 International License. 


\section{Patient consent}

Informed consent for genetic studies, publication of case reports and accompanying images have been obtained from all patients or their tutors of both families. The treatment of human subjects complies with the Declaration of Helsinki, and the Research Ethics Committee of IRCCS Istituto Auxologico Italiano approved the study.

\section{Acknowledgements}

The authors would like to thank the family members for their collaboration. They also thank Dr Milena Perotti (Department of Geriatrics and Cardiovascular Medicine, IRCCS Istituto Auxologico Italiano, Milan) for contributing to the UMS database.

\section{References}

1 Packham EA \& Brook JD. T-box genes in human disorders. Human Molecular Genetics 200312 R37-R44. (https://doi.org/10.1093/hmg/ ddg077)

2 Kunasegaran K, Ho V, Chang TH, De Silva D, Bakker ML, Christoffels VM \& Pietersen AM. Transcriptional repressor Tbx3 is required for the hormone-sensing cell lineage in mammary epithelium. PLoS ONE 20149 e110191. (https://doi.org/10.1371/ journal.pone.0110191)

3 Bamshad M, Root S \& Carey JC. Clinical analysis of a large kindred with the Pallister ulnar-mammary syndrome. American Journal of Medical Genetics 199665 325-331. (https://doi. org/10.1002/(SICI)1096-8628(19961111)65:4<325::AIDAJMG15>3.0.CO;2-W)

4 Pallister PD, Herrmann J \& Opitz JM. Studies of malformation syndromes in man XXXXII: a pleiotropic dominant mutation affecting skeletal, sexual and apocrine-mammary development. Birth Defects Original Article Series 197612 247-254.

5 Schinzel A, Illig R \& Prader A. The ulnar-mammary syndrome: an autosomal dominant pleiotropic gene. Clinical Genetics 198732 160-168. (https://doi.org/10.1111/j.1399-0004.1987.tb03347.x)

6 Bamshad M, Le T, Watkins WS, Dixon ME, Kramer BE, Roeder AD, Carey JC, Root S, Schinzel A, Van Maldergem L, et al. The spectrum of mutations in TBX3: genotype/Phenotype relationship in ulnarmammary syndrome. American Journal of Human Genetics 199964 1550-1562. (https://doi.org/10.1086/302417)

7 Wollnik B, Kayserili H, Uyguner O, Tukel T \& Yuksel-Apak M. Haploinsufficiency of TBX3 causes ulnar-mammary syndrome in a large Turkish family. Annals of Genetics 200245 213-217. (https:// doi.org/10.1016/S0003-3995(02)01144-9)

8 Sasaki G, Ogata T, Ishii T, Hasegawa T, Sato S \& Matsuo N. Novel mutation of TBX3 in a Japanese family with ulnar-mammary syndrome: implication for impaired sex development. American Journal of Medical Genetics 2002110 365-369. (https://doi. org/10.1002/ajmg.10447)

9 Tanteles GA, Nicolaou N, Syrimis A, Metaxa R, Nicolaou M, Christophidou-Anastasiadou V \& Skordis N. Novel TBX3 mutation in a family of Cypriot ancestry with ulnar-mammary syndrome. Clinical Dysmorphology 201726 61-65. (https://doi.org/10.1097/ MCD.0000000000000170)

10 Franceschini P, Vardeu MP, Dalforno L, Signorile F, Franceschini D, Lala R \& Matarazzo P. Possible relationship between ulnar-mammary syndrome and split hand with aplasia of the ulna syndrome. American Journal of Medical Genetics 199244 807-812. (https://doi org/10.1002/ajmg.1320440618)

11 Linden H, Williams R, King J \& Blair E. Ulnar Mammary syndrome and TBX3: expanding the phenotype. American Journal of Medical Genetics A 2009 149A 2809-2812. (https://doi.org/10.1002/ ajmg.a.33096)
12 Joss S, Kini U, Fisher R, Mundlos S, Prescott K, Newbury-Ecob R \& Tolmie J. The face of Ulnar Mammary syndrome? European Journal of Medical Genetics 201154 301-315. (https://doi.org/10.1016/j. ejmg.2010.12.010)

13 de Filippis T, Gelmini G, Paraboschi E, Vigone MC, Di Frenna M, Marelli F, Bonomi M, Cassio A, Larizza D, Moro M, et al. A frequent oligogenic involvement in congenital hypothyroidism. Human Molecular Genetics 201726 2507-2514. (https://doi.org/10.1093/ $\mathrm{hmg} / \mathrm{ddx} 145$ )

14 Dong C, Wei P, Jian X, Gibbs R, Boerwinkle E, Wang K \& Liu X. Comparison and integration of deleteriousness prediction methods for nonsynonymous SNVs in whole exome sequencing studies. Human Molecular Genetics 201524 2125-2137. (https://doi. org/10.1093/hmg/ddu733)

15 Joustra SD, van der Plas EM, Goede J, Oostdijk W, Delemarre-van de Waal HA, Hack WW, van Buuren S \& Wit JM. New reference charts for testicular volume in Dutch children and adolescents allow the calculation of standard deviation scores. Acta Paediatrica 2015104 e271-e278. (https://doi.org/10.1111/apa.12972)

16 Dwyer AA, Sykiotis GP, Hayes FJ, Boepple PA, Lee H, Loughlin KR, Dym M, Sluss PM, Crowley WF Jr \& Pitteloud N. Trial of recombinant follicle-stimulating hormone pretreatment for $\mathrm{GnRH}$ induced fertility in patients with congenital hypogonadotropic hypogonadism. Journal of Clinical Endocrinology and Metabolism 2013 98 E1790-E1795. (https://doi.org/10.1210/jc.2013-2518)

17 Boehm U, Bouloux PM, Dattani MT, de Roux N, Dodé C, Dunkel L, Dwyer AA, Giacobini P, Hardelin JP, Juul A, et al. Expert consensus document: European Consensus Statement on congenital hypogonadotropic hypogonadism--pathogenesis, diagnosis and treatment. Nature Reviews Endocrinology 201511 547-564. (https:// doi.org/10.1038/nrendo.2015.112)

18 Dwyer AA, Raivio T \& Pitteloud N. Gonadotrophin replacement for induction of fertility in hypogonadal men. Best Practice and Research Clinical Endocrinology and Metabolism 201529 91-103. (https://doi. org/10.1016/j.beem.2014.10.005)

19 Bamshad M, Lin RC, Law DJ, Watkins WC, Krakowiak PA, Moore ME, Franceschini P, Lala R, Holmes LB, Gebuhr TC, Bruneau BG, et al. Mutations in human TBX3 alter limb, apocrine and genital development in ulnar-mammary syndrome. Nature Genetics 199716 311-315. (https://doi.org/10.1038/ng0797-311)

20 Meneghini V, Odent S, Platonova N, Egeo A \& Merlo GR. Novel TBX3 mutation data in families with ulnar-mammary syndrome indicate a genotype-phenotype relationship: mutations that do not disrupt the T-domain are associated with less severe limb defects. European Journal of Medical Genetics 200649 151-158. (https://doi. org/10.1016/j.ejmg.2005.04.021)

21 Lingbeek ME, Jacobs JJ \& van Lohuizen M. The T-box repressors TBX2 and TBX3 specifically regulate the tumor suppressor gene p14ARF via a variant T-site in the initiator. Journal of Biological Chemistry 2002277 26120-26127. (https://doi.org/10.1074/jbc. M200403200)

22 Carlson H, Ota S, Campbell CE \& Hurlin PJ. A dominant repression domain in Tbx3 mediates transcriptional repression and cell immortalization: relevance to mutations in Tbx3 that cause ulnarmammary syndrome. Human Molecular Genetics 200110 2403-2413. (https://doi.org/10.1093/hmg/10.21.2403)

23 Bonomi M, Vezzoli V, Krausz C, Guizzardi F, Vezzani S, Simoni M, Bassi I, Duminuco P, Di Iorgi N, Giavoli C, et al. Characteristics of a nationwide cohort of patients presenting with isolated hypogonadotropic hypogonadism (IHH). European Journal of Endocrinology 2018178 23-32. (https://doi.org/10.1530/EJE-17-0065)

24 Pitteloud N, Hayes FJ, Boepple PA, DeCruz S, Seminara SB, MacLaughlin DT \& Crowley WF Jr. The role of prior pubertal development, biochemical markers of testicular maturation, and genetics in elucidating the phenotypic heterogeneity of idiopathic hypogonadotropic hypogonadism. Journal of Clinical Endocrinology

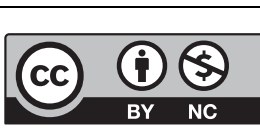


and Metabolism 200287 152-160. (https://doi.org/10.1210/ jcem.87.1.8131)

25 Trabado S, Maione L, Bry-Gauillard H, Affres H, Salenave S, Sarfati J, Bouvattier C, Delemer B, Chanson P, Le Bouc Y, et al. Insulin-like peptide 3 (INSL3) in men with congenital hypogonadotropic hypogonadism/Kallmann syndrome and effects of different modalities of hormonal treatment: a single-center study of 281 patients. Journal of Clinical Endocrinology and Metabolism 201499 E268-E275. (https://doi.org/10.1210/jc.2013-2288)

26 Young J. Approach to the male patient with congenital hypogonadotropic hypogonadism. Journal of Clinical Endocrinology and Metabolism 201297 707-718. (https://doi.org/10.1210/jc.20111664)
27 Kelberman D \& Dattani MT. The role of transcription factors implicated in anterior pituitary development in the aetiology of congenital hypopituitarism. Annals of Medicine 200638 560-577. (https://doi.org/10.1080/07853890600994963)

28 Pontecorvi M, Goding CR, Richardson WD \& Kessaris N. Expression of Tbx 2 and Tbx 3 in the developing hypothalamic-pituitary axis. Gene Expression Patterns 20088 411-417. (https://doi.org/10.1016/j. gep.2008.04.006)

29 Trowe MO, Zhao L, Weiss AC, Christoffels V, Epstein DJ \& Kispert A. Inhibition of Sox2-dependent activation of Shh in the ventral diencephalon by Tbx3 is required for formation of the neurohypophysis. Development 2013140 2299-2309. (https://doi. org/10.1242/dev.094524)

Received in final form 11 November 2018

Accepted 23 November 2018

Accepted Preprint published online 23 November 2018

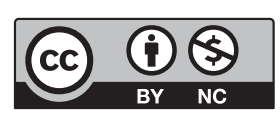

This work is licensed under a Creative Commons Attribution-NonCommercial 4.0 International License. 